OAKuey, C. L. \& Warrack, G. H. (1958). J. gen. Microbiol. 18, 9-12

\title{
The Cysteine-Inactivated Proteinase ( $\delta$-antigen) of Clostridium histolyticum
}

\author{
BY C. L. OAKLEY AND G. HARRIET WARRACK \\ The Bacteriology Department, School of Medicine, Leeds, and the \\ Wellcome Research Laboratories, Beckenham, Kent
}

SUMMARY : Evidence is provided in support of the view of MacLennan, Mandl \& Howes (1958) that some strains of Clostridium histolyticum produce a cysteineinactivated proteinase-the $\delta$-antigen.

Three soluble antigens in Clostridium histolyticum filtrates have been differentiated by immunological means: the necrotizing and lethal toxin $\alpha$, the collagenase $\beta$, and the cysteine-activated proteinase $\gamma$. Though the existence of a cysteine-inactivated proteinase had been demonstrated by van Heyningen (1940), Oakley \& Warrack (1950) were unable to show its presence in the culture filtrates they had used to differentiate the $\alpha$-, $\beta$ - and $\gamma$-antigens. Since then Mandl, MacLennan \& Howes (1953) and MacLennan, Mandl \& Howes $(1958)$ have found a cysteine-inactivated proteinase $(\delta$-antigen $)$ in some filtrates of $C$. histolyticum cultures examined by them, and we here provide some evidence to support their views.

\section{METHODS}

Culture filtrate preparations. Through the courtesy of Dr J. D. MacLennan we received six dried partly purified preparations from filtrates of Clostridium histolyticum: P199, P208, P235, P245, P278 and P279.

Antisera. We used the six Clostridium histolyticum antisera referred to by Oakley \& Warrack (1950).

Diluents. A mixture of equal volumes of sodium chloride solution $(1 \%$, $\mathrm{w} / \mathrm{v}$ ) and broth (broth + saline) was used as a non-activating diluent. For activation with cysteine the culture filtrate preparations were dissolved in $0 \cdot 1 \mathrm{M}$-cysteine (neutralized) made by dissolving cysteine in a little distilled water, adjusting the $\mathrm{pH}$ value to $\mathbf{7 \cdot 1 - 7 \cdot 3}$ (checked electrometrically) and diluting the mixture to $0 \cdot 1 \mathrm{M}$-cysteine with distilled water.

Assay of antisera. The antisera were assayed by conventional methods against RR 2001 (100 units/ml.) as standard, with azocoll as indicator (Oakley, Warrack \& van Heyningen, 1946). The level of test was 0.25 unit, and the standard indicating effect was the release of a certain amount of 'colour' from the azocoll. A suitable end-point tube was chosen from the assay of the standard serum that was always included in any set of tests, and used to determine the end-point, by interpolation when necessary, in tests of other sera. In tests with cysteine-activated filtrates, the tubes should be filled nearly to the top to prevent oxidation of the cysteine. The values given in the Tables are the average of at least three determinations: the error of a single test appears to be about $20 \%$. 


\section{RESULTS}

\section{Activity of the preparations}

All the preparations, dissolved in broth + saline, rapidly dissolved azocoll, releasing 'colour'; they had little or no effect on collagen paper, and no necrotizing effect on intradermal injection into guinea-pig's skin. Solution in cysteine increased the effect on azocoll of all preparations except P245, whose activity was decreased.

\section{Effect of cysteine on the test dose of the filtrate preparations}

As Table 1 shows, the test doses of these preparations were invariably altered by solution in cysteine, as compared with those of material dissolved in broth + saline. In all but P245 the test dose was much decreased; in P245 it was increased twofold. Oakley \& Warrack (1950) have already shown that the gamma antigen of Clostridium histolyticum is activated by cysteine, so that solution in cysteine, if it affected the test dose at all, would be expected to decrease it, if gamma were the only antigen affected. The fact that the test dose of P245 was increased by solution in cysteine suggests that a cysteineinactivated antigen was present in the preparation.

Table 1. Test doses of Clostridium histolyticum filtrate preparations dissolved in broth + saline or in neutralized $0.1 \mathrm{M}-c y$ steine

Test dose (mg.) of preparation dissolved in

\begin{tabular}{|c|c|c|c|}
\hline \multirow[b]{2}{*}{$\begin{array}{l}\text { Filtrate } \\
\text { preparation }\end{array}$} & & \multirow[b]{2}{*}{$\frac{\text { test dose in broth saline }}{\text { test dose in cysteine }}$} \\
\hline & Broth + saline & $\begin{array}{l}\text { Neutralized } 0 \cdot 1 \mathrm{M}- \\
\text { cysteine }\end{array}$ & \\
\hline P 199 & $0 \cdot 125$ & 0.062 & 2 \\
\hline P208 & $0 \cdot 125$ & 0.018 & 7 \\
\hline P235 & 0.44 & 0.021 & 21 \\
\hline P245 & $0 \cdot 38$ & 0.68 & 0.5 \\
\hline P278 & $0 \cdot 20$ & $0 \cdot 023$ & 9 \\
\hline P279 & $0 \cdot 20$ & 0.022 & 9 \\
\hline
\end{tabular}

Tahle 2. Values of antisera against Clostridium histolyticum filtrate preparations dissolved in broth + saline, with azocoll as indicator

\begin{tabular}{lccccccccc}
\multicolumn{10}{c}{ Values of sera against } \\
Serum & $\alpha$-antigen & $\beta$-antigen & $\gamma$-antigen & P 199 P208 & P235 & P 245 P278 P279 \\
RR 2001* & 100 & 100 & 100 & 100 & 100 & 100 & 100 & 100 & 100 \\
RR 2005 & 240 & 350 & 160 & 90 & 90 & 80 & 75 & 70 & 80 \\
RR 2008 & 27 & 380 & 360 & 165 & 170 & $40-160 \dagger$ & 175 & 150 & 160 \\
RR 2035 & 570 & 250 & 150 & 200 & 185 & $100-400$ & 185 & 170 & 200 \\
RR 8003 & 55 & 210 & 550 & 125 & 125 & $60-240$ & 120 & 130 & 120 \\
RR 8006 & 73 & 160 & 410 & 150 & 140 & $80-320$ & 150 & 140 & 140 \\
$*$ & Standard. & $\dagger$ & Inadequate amounts of preparation for closer test.
\end{tabular}

Values of antisera against partly-purified filtrate preparations dissolved in broth + saline

Table 2 gives the values of the six antisera against the known Clostridium histolyticum antigens for comparison with their values against the purified preparations. It is clear that the latter figures bear no relationship to the 
values against the $\alpha$-, $\beta$ - or $\gamma$-antigen; we may therefore postulate another antigen $(\delta)$ as that responsible for the end-points in these tests.

\section{Effect on antiserum values of solution of the filtrate preparations in cysteine}

As Table 3 shows, solution of the preparations in cysteine had a considerable effect on the antisera assayed against them. Most of the values obtained in these tests agree very well with the anti- $\gamma$ values of the antisera, if one allows for the accuracy of the tests; the values for antiserum RR 2005, and that for antiserum RR8003 against filtrate preparation P245, are however, rather lower than the known anti- $\gamma$ values, and may be due to some other antigenic proteinase. When these results are compared with those for the change in test dose produced by solution in cysteine, it is clear that delta antigen is inactivated by cysteine.

Table 3. Values of antisera against Clostridium histolyticum filtrate preparations dissolved in neutralized $0.1 \mathrm{M}$-cysteine, with azocoll as indicator

\begin{tabular}{|c|c|c|c|c|c|c|c|c|c|}
\hline \multirow[b]{2}{*}{ Serum } & \multicolumn{9}{|c|}{ Values of sera against } \\
\hline & $\begin{array}{c}\alpha \text {-anti- } \\
\text { gen }\end{array}$ & $\begin{array}{c}\beta \text {-anti- } \\
\text { gen }\end{array}$ & $\begin{array}{c}\gamma \text {-anti- } \\
\text { gen }\end{array}$ & P 199 & P208 & P235 & P245 & P278 & P279 \\
\hline RR 2001* & 100 & 100 & 100 & 100 & 100 & 100 & 100 & 100 & 100 \\
\hline RR 2005 & 240 & 350 & 160 & 110 & 115 & 115 & 100 & 125 & 120 \\
\hline RR 2008 & 27 & 380 & 360 & 415 & 475 & 475 & 310 & 530 & 510 \\
\hline RR2035 & 570 & 250 & 150 & 230 & 220 & 230 & 180 & 275 & 245 \\
\hline RR 8003 & $\mathbf{5 5}$ & 210 & $\mathbf{5 5 0}$ & 530 & 630 & 710 & 380 & 750 & 650 \\
\hline RR 8006 & 73 & 160 & 410 & 350 & 390 & 470 & 300 & 450 & 400 \\
\hline
\end{tabular}

\section{DISCUSSION}

It is evident that when a culture-filtrate preparation contains a cysteineactivated and a cysteine-inactivated proteinase, solution of the preparation in cysteine will increase its activity, leave it unaffected, or decrease it, depending on the relative amounts of the two components and on the concentration of activating substances present. If we take the test doses of the filtrates in broth + saline as inversely proportional to their $\delta$-antigen content, and those in cysteine as inversely proportional to the $\gamma$-antigen content, it is clear that a very considerable degree of purification has been obtained in some of them. Thus, at one end of the scale filtrate preparation P245 has a $\gamma: \delta$ ratio of about $0.5: 1$, whereas filtrate preparation P235, at the other, has a $\gamma: \delta$ ratio of 21:1, a forty-fold increase in purity for $\gamma$-antigen. The other preparations show intermediate increases in purity. Obviously the presence of other reducing agents in the broth + saline solutions may decrease their $\delta$ activity slightly, and thus slightly alter these ratios, but judging from the amount of cysteine necessary for complete inactivation of $\delta$-antigens, this effect is very small. The $\delta$-antigen is not destroyed by cysteine, for when the cysteine is oxidized by shaking the mixture with air the $\delta$ values are obtained when the shaken preparation is being used as antigen in serum assays. 


\section{REFERENCES}

van Heyningen, W. E. (1940). The proteinases of Cl. histolyticum. Biochem. J. 34, 1540.

MacLennan, J. D., Mandu, I. \& Howes, E. L. (1958). New proteolytic enzymes from Cl. histolyticum filtrates. J. gen. Microbiol. 18, 1.

Mandl, I., Maclennan, J. D., \& Howes, E. L. (1953). Isolation and characterisation of proteinase and collagenase from $\mathrm{Cl}$. histolyticum. J. clin. Invest. 32, 1323.

OAKLEY, C. L. \& WARrack, G. H. (1950). The alpha, beta and gamma antigens of Clostridium histolyticum (Weinberg and Séguin, 1916). J. gen. Microbiol. 4, 365.

Oakley, C. L., Warrack, G. H. \& van Heyningen, W. E. (1946). The collagenase ( $\kappa$-toxin) of $\mathrm{Cl}$. welchii type A. J. Path. Bact. 58, 229.

(Received 20 February 1957) 